\title{
URBANISM AND SECURITY ASPECTS OF INCLUSION AND REGIONAL MIGRATION
}

\author{
Hana Vykopalová
}

\begin{abstract}
The submitted contribution responds to the current global migration and integration issues. It presents a comparison of the knowledge in areas of social inclusion, social exclusion and social cohesion and their interrelations. It points to basic theoretical starting points and concepts solving social exclusion, to the dimensions of social inclusion from the perspective of including marginal groups in the majority society, and to the importance of social capital. It provides a basic analytical and comparative orientation in the field of social inclusion from the perspective of immigration and those socially excluded or at risk of social exclusion. It provides basic information on basic initiatives in the field of social inclusion within the EU, presents a practical project aimed at solving the social integration of people excluded or at risk of social exclusion at the regional level as innovative solutions and aspect of originality. Practical applications in different countries are related to public and social politics. Comparative analysis and research reports have provided an adequate level of knowledge about the problem.
\end{abstract}

\section{Keywords}

social inclusion, social exclusion, integration, integration policy, social integration programs at regional level

\section{Introduction}

Individuals as well as the society as a whole understand the process of social inclusion as an attempt to share the same values and equal access to the qualities of life. Processes of social inclusion have been a permanent part of the existence of human society, they closely relate to the social order. Historically, social inclusion processes have been closely linked to migration. In almost every society, marginal social groups emerged in certain periods and situations, unable to use all social opportunities on an equal footing with others. Development of democracy, the declaration of freedoms and equal opportunities, and the emergence of social order, brought about a more intense perception of social inclusion issues. The aim of the contribution is to point out the basic aspects of social 
exclusion, cohesion and social inclusion and their mutual conditionality. Social inclusion issues are not only relevant in the context of the global migration crisis, as almost every country addresses the problem of social inclusion in the context of so-called cultural exclusion, in the case of socially excluded groups. A number of well-known authors deal with these issues, for example: Kelsey, 2019; Bucheli, Fontenla, \& Waddell, 2019; Yagmur, 2019; Pajnik, 2019; Pūraitè, Seniutienè, \& Greičius 2017; Reslow, 2019; Valenta et al., 2019; Bartram, 2019 and others.

\section{Social exclusion as a fundamental starting point. Basic theoretical background and description of the problem.}

The starting point for addressing social inclusion issues lies in the lessons learned from the solution of social exclusion, the essence of which lies in the inability of the society to integrate all its members. The current concept of social exclusion builds on the concept of poverty as material deprivation causing social disadvantage and structured inequality. From this perspective, social exclusion is perceived as a multidimensional and dynamic phenomenon (Room, 1999). However, issues of social exclusion as a multidimensional phenomenon may also include relational aspects, within social interactions and communication through which the social exclusion process interferes, as well as social aspects of socially excluded persons due to disadvantageous social situations and conditions, referred to as social disadvantages (Sirovátka, 2003; Navrátil \& Šimíková, 2002). Many other researches have a similar view on social exclusion. For example, Kolibová (2008) emphasizes the constructivist aspect, focusing on the social, economic and political criteria. The need to integrate socially excluded people into the society intensified in Europe at the end of the last century, with more attention paid to the unequal or limited access to economic assets, but also to the citizenship in terms of insufficient participation in the field of justice, security, education and representation (Atkinson, 2000; Rodgers, 1995). Although there is still a strong correlation between social exclusion and poverty, the dominant problem today is the exclusion of personal relationships, the so-called strength of the bond that binds individuals and groups as a whole. An example of this is the increasing proportion of immigrants from non-European cultures, accompanied by the reluctance of the majority in European countries to integrate the immigrants, as well as the reluctance of an increasing number of immigrants to integrate. Their aim is rather to colonize the occupied space by transmission and preservation of their own culture (Sartori, 2005). Some Czech researchers point to a similar issue in their studies of social exclusion and excluded localities, with an emphasis on the social dimension of exclusion - when social exclusion is related to membership in organizations, interpersonal and institutional trust, anomic attitudes, social capital, or ethnicity. Other factors of social exclusion, such as housing, finance, consumption, etc., are addressed systemically (Topinka, 2015). Through interactive maps, we can see almost immediately information on the nature of the locations, their size, sources of funding and involvement in support projects.

Therefore, Drbohlav (2016), who in the context of the migration crisis talks about a new form of integration and the need for social inclusion, speaks of a new integration model 
called the "model of civic integration" based on the possibility of preserving one's own cultural specificity, but otherwise fully participating in economic self-sufficiency, as well as language, legislative and civic integrity in the majority society.

However, the issues of social exclusion and inclusion also have a formal and informal level. The formal area includes the public and legislative layer, governing relations with the state and society. The informal area is marked by a purely private relationship, based on unenforceable facts, such as sharing values, traditions, social ties. Both these aspects of social exclusion are of great importance when developing inclusive measures for the society and their subsequent effectiveness.

\section{Dimensions of Social Inclusion - the question of the importance of social capital for society - comparative basis}

Social inclusion is understood as inclusion of a marginal group into the majority society in situations where basic social parameters are known: delimitation of territory (borders), nationality, age, education, etc. Social inclusion is therefore always a specific individual situation that has its intensity, quality and degrees. In terms of formal inclusion, we distinguish between "inclusion-cum-entry" and "inclusion-cum-citizenship" (Goodin, 1996). The so-called inclusion-cum-entry allows living on a given territory, but with the restriction of other civil and social rights. Inclusion-cum-citizenship is considered as a higher level of inclusion, where active participation in social life and participation in the life of the majority society is possible, including the need to comply with the country's legislation. Another type of inclusion is so-called "parcel inclusion", where individuals have access to certain areas of action, but because their inclusion is not complete, they do not have enough influence to achieve a more significant effect, which is seen as an alienation of the system. The opposite example is a monological inclusion that indicates the overall assimilation of the individual (Mouzelis, 1995). The dimensions of social inclusion significantly affect social capital. The concept of social capital has different representations in the works of many authors. Putnam understands social capital as a macro-sociological phenomenon and a community issue. According to him, social capital is not primarily related to an individual, but to higher social units and to the society as a whole (Putnam, 1995; Coleman, 1988). Social capital in the form of social networks, standards, social trust, co-ordination and co-operation represents a positive mutual benefit for the participating parties and the social environment in which they live (Putnam, 1995). The social capital has several levels in which it takes place, including the micro-level of interpersonal relations, the mezzo-level of societies and organizations and the macro-level of social institutions (Falk \& Kilpatric, 1999). At present, the highest importance is attributed to the level of interpersonal relations that is based on the structure of social relations networks related to group membership. "Social capital also involves the transformation of relationships, such as neighborhoods or working groups, which are both necessary and voluntary, and which result in a subjective feeling of duty, gratitude, respect, friendship, etc." (Bourdieu, 1983, p. 248). 
The manifestations of social capital at the level of social groups are subject to intensive discussions. Narayan (1999) perceives social capital as a connecting factor influencing both formal and informal groups and institutions. However, strong social capital in a group does not have to have a positive effect on the society if the shared values and standards are dangerous (Gambetta, 1988).

Social capital and social cohesion are closely related phenomena, having formal and informal forms, manifested in a cross-sectional manner, at the level of a group and a state, or other large units. As an example, the concept of social cohesion in EU Reporting is based on the following dimensions: a) reduction of inequalities and social exclusion, b) strengthening of social relations, interactions and bonds, which closely relates to the social capital of the society (Berger-Schmitt, 2000). In the EU's policy, the cohesion strategy is an important policy objective that is implemented through the process of socio-economic convergence and the creation of joint institutions at European level (Leonardi, 2005). The occurrence of unemployment, the risk of poverty and the aging population represent a significant risk and barrier to social cohesion, which is eliminated by mutual regional cooperation, with an emphasis on economic, social and territorial cohesion. One of the key initiatives for addressing social inclusion in the EU is the so-called Lisbon Strategy (2004) aiming to make Europe one of the most dynamic and competitive economies based on knowledge, sustainable growth and a high-quality labor market, promoting social cohesion and combating exclusion with the aim of modernizing the European social model and investing in people. On the basis of these documents, the so called NAPs on Social Inclusion were published, with the objective to structure social policy in individual member countries based on structural indicators. Social exclusion, social inclusion, and social cohesion are concepts involving broad discourse on many levels, with a number of widely differing views. Social cohesion is seen as a condition for the stability of the political system and security; it influences the quality of political institutions and contributes to economic growth, it facilitates the application of social reforms (Easterly, Ritzen, \& Woolcock, 2006). On the other hand, many authors perceive social exclusion as a social evil, since it is in many ways unfair and it disturbs social cohesion (Lister, 2003).

\section{Social inclusion - concept definitiv}

At present, social inclusion is one of the most discussed issues in the society. It relates to the integration of immigrants into the majority society. Factors strongly influencing this process are closely monitored. In the context of studying social integration of immigrants in Europe since 1960s, individual generations of immigrants and the process of their integration have been monitored. However, the integration process is also influenced by the differences in integration policy and its concepts, which differ by country. Integration theories supported by empirical research have identified factors that have a significant impact on the integration of immigrants into mainstream society. According to these theories, integration increases with the length of stay, which is connected with an effort to learn, to build relationships, to discover cultural specifics and learn the language. Studies focusing on the integration of foreigners point to the importance of primary socialization 
in the host country, which is also related to age. The lower the immigrant's age, the higher the integration. Immigrants arriving in the country as children are likely to be more integrated than their parents. They will attend school in the host country as well as spend the most formative years shaping their personal identity (Simon, 2003). Researches point to another criterion of integration, which is the influence of education and the employment status of immigrants before leaving their home country (Gang \& Stuart, 2000; Fokkema \& de Haas, 2011), as well as gender roles that can influence integration processes from the viewpoint of evaluating social opportunities and establishing relationships and cultural integration. The housing arrangement proves to be a significant criterion of integration as it implies certain social anchorage. Joint housing with other family members assumes a higher degree of integration than housing with non-family members or living single. Preferring "residential" housing also shows a certain level of integration, living close to one's compatriots with the possibility of maintaining social ties, which strengthens the integrity of the ethnic group but weakens integration into the majority society (Massey \& Denton, 1985). Some researches consider the presence of children to be a positive integration element, too. Children develop relations with their peers much more easy and naturally, and through the peers also with the adults, thus forming the basis for social facilitation and making social inclusion easier (Sampson, 1988; Völker, Flap, \& Lindenberg, 2007).

The concept of "underclass" appears in the context of the migration crisis or social exclusion accompanied by social concentration. This concept represents the so-called cultural concentration, exclusion known as "the culture of poverty" (Lewis, 1969) in the form of slums, where, along with the classic social policy tools, social work and community projects are being put into practice. This form of social exclusion has a number of contradictory adaptation mechanisms aimed at the mode of survival accompanied by isolation from the rest of the society, with the absence of traditional social institutions such as civil society, churches or political parties. The character of this environment, along with specific adaptation mechanisms, reduces the likelihood of escape and, on the contrary, creates a lifestyle of chronic dependence on the welfare state reducing the possibilities for inclusion in the majority society.

Ways and strategies for inclusion are chosen depending on the consideration of the causes of social exclusion. However, due to the complexity of this phenomenon, these strategies mutually intertwine. In practice, we distinguish between individual (moral) failure and the accumulation of objective causes of disadvantage (Layte \& Whelan, 2003).

Based on an assessment of the causes of social exclusion, various social policy instruments are implemented: a) a re-distributive approach aimed at the eradication of poverty mainly through social security benefits; b) an integrative approach where the basic mechanism of social inclusion is paid employment, community inclusion and overcoming social isolation; and c) a patronizing approach when the reason for social exclusion of certain persons is in their pathological, moral and cultural characteristics, and the fundamental mechanism for their inclusion is their re-socialization through social work intervention, crisis social intervention or repressive public policies (Levitas, 2000). 


\section{Questions about methodology and research}

With the help of specialized literature and research papers by leading specialists, a descriptive comparative and analytical conceptual part was prepared. The case study "Implementation of a social inclusion program at the regional level - Ostrava, Czech Republic" is based on comparative, quantitative and qualitative findings and data processed within the framework of regional and national statistical records of inhabitants and documents of the Statutory City of Ostrava and using secondary data sources from existing materials and surveys that were conducted in Ostrava. The theoretical-analytical descriptive part dealing with the comparison of individual approaches and opinions has provided answers to questions in the area of implementation of questions related to the clarification and description of the development of social exclusion and social segregation as an accompanying phenomenon of a number of other social phenomena, such as deindustrialisation, decline in economic growth and demographic regressive changes. Regional migration is thus becoming an integral part of urban development known as shrinking cities. Due to their topicality, these issues are constantly being discussed in various forums, workshops and discussions, where possible tools are constantly being sought to strengthen the inclusion of marginalized groups in society and to strengthen its social stability. Qualitative knowledge focused on the assessment of group links and social cohesion in minority groups, as another element leading to greater social integrity, also bring significant information.

\section{Implementation of a social inclusion program (socially excluded groups) at the re- gional level - Ostrava, Czech Republic, case study}

Given that the Czech Republic is not a target country for migration and there has been no increase in the number of asylum seekers in recent decades, attention is paid to the inclusion of individuals and groups of citizens socially excluded and at risk of social exclusion, living mostly in excluded localities. As a result of social exclusion, problematic behavior and the occurrence of crime with these groups. The Moravian-Silesian region is one of the most critical regions in terms of unemployment and the occurrence of excluded localities, with Ostrava as the largest city.

In the 15 socially excluded localities in Ostrava live up to 6,520 people, there are also 42 hostels with approved rules of operation for 7,231 beds. There are 12 shelters in Ostrava with a total capacity of 412 people. There are three dormitories in Ostrava with a total capacity of 120 beds. The network of social services for people in need is also formed by two low-threshold day centers, which are for men and women with a total of 125 seats. (Source: Labor Office of the Czech Republic - regional branch in Ostrava, contact office Ostrava, June 2017)

The situation for people at risk of social exclusion, people living in socially excluded localities and homeless people seems to be critical from the social assistance point of view. High unemployment, an aging population, an increase in the post-productive age 
population and changes in labor market requirements contribute to the high dependence of the population on various forms of social assistance, which are additional charges for housing, benefits in material need and housing benefit. Long-term measures such as the Concept of Social Housing of the Czech Republic 2015-2025 and the Strategic Plan for Social Inclusion Ostrava 2015-2018 are adopted to improve the situation.

\section{Chart 1 Recipients of social assistance and housing benefits to the total population of the city}

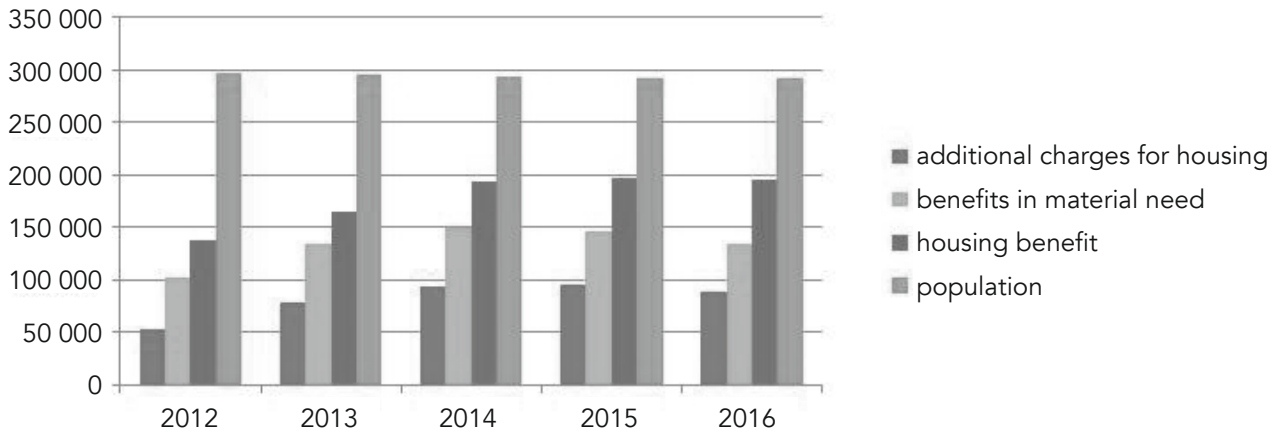

Source: Labor Office of the Czech Republic (n.d.)

Ostrava is the third largest city in the Czech Republic in terms of size and population. It used to be a major center of coal mining and metallurgy, and has undergone significant changes since 1989. As a result of the restructuring of the industry, mining activity gradually declined and Ostrava transforms into a city with other functions. Industrial restructuring brings along different labor requirements, which is accompanied by relatively high unemployment, with all accompanying phenomena, including a change in population composition.

From 1991 to the present, Ostrava registered a systematic decline in the number of people, this decline was most significant in 2010. Inhabitants and people moving out of the city are mainly those in pre-productive and productive age, thus the rise in the age index in Ostrava is 50 \% higher than in other comparable cities. Demographic forecasts suggest a significant decline in the number of people up to 34 years of age, and the largest population group will be people aged 50-54 and older. The average unemployment rate in 2005-2012 was $150 \%$ of the Czech Republic's level and it is significantly higher than in the reference cities and this trend continues. These negative effects do not provide positive prognostic assumptions for improving the situation. Given the historical development and traditional structure of industry in the region, the structure of the education of the population is lower compared to the reference cities. Ostrava offers fewer work opportunities and unemployment is expanding.

The current level of crime in Ostrava is among the highest in the Czech Republic (Czech Statistical Office). 
Based on these facts, the city of Ostrava presented since 2011 long-term comprehensive social inclusion program, with an aim to improve the coexistence of the city's inhabitants. The program included 12 integrated projects and was based on three main pillars: employment, education and housing. The target group consisted of individuals, groups of individuals, larger groups or communities that had a difficult or restricted access to resources and opportunities to engage in the social, economic and political activities of the majority society.

The program was implemented in two phases, the first stage took place in 2012-2013, when the program was launched, first families joined, the program's functionality was tested and partners were selected. The second stage was set for the period 2014-2020 and includes a number of specific objectives such as: raising the educational level and reducing long-term unemployment of the inhabitants living in excluded localities, increasing the quality of housing and many more (Statutory City of Ostrava, n.d.).

The trend of decreasing urban population, deepening social inequality and social segregation is leading to the emergence of the so-called "urban shrinkage" (Großmann et al., 2008, p. 85-87) concept of shrinking cities, which is due to deinstustrialization and economic downturn and leads to interregional migration.

\section{Chart 2 Critical indicators of shrinking city (urban shrikage)}

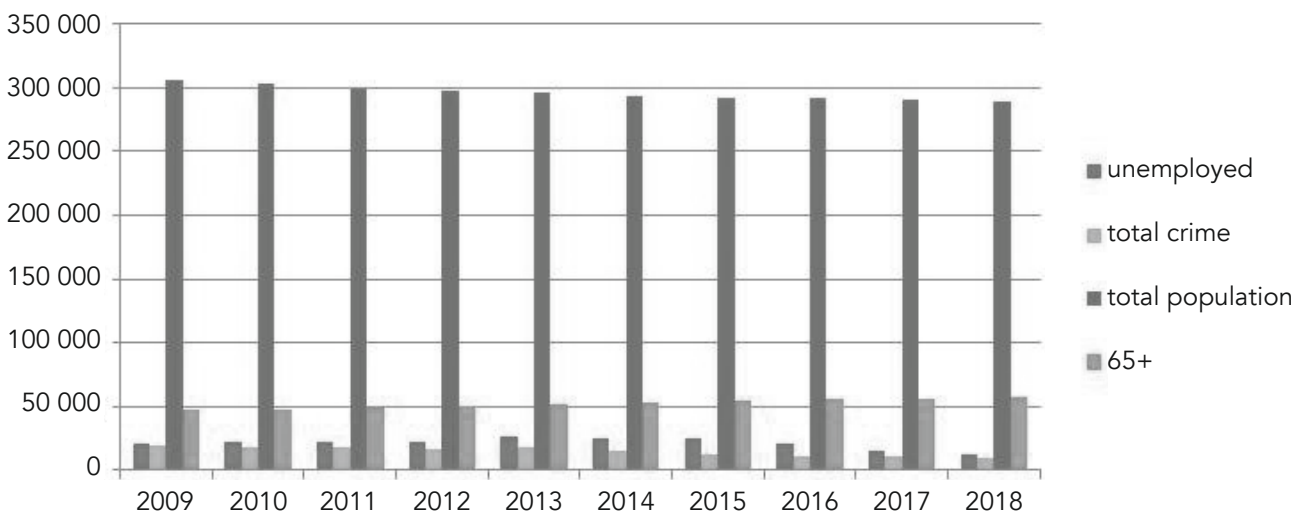

Source: Čsú. Český statistický úřad [Czech Statistical Office]. (n.d.)

Based on the analysis of statistical data on the population, procedures are being developed to identify residential segregation sites. However, in many cases, these practices are ineffective because they are influenced by more dominant factors such as natural demographic effects (aging of the population, reduced birth rates), deindustrialisation, reduced economic growth and the negative effects of suburbanization (urban sprawl). This trend is characterized by a number of large European cities that have undergone industrial transformation, and will gradually become an expected social trend. Only the evaluation of the implementation of long-term programs of social inclusion will provide an answer to the effectiveness of this idea. 


\section{Summary}

Social inclusion appears to be a rather complex, multidimensional, all-society problem with a number of other social contexts, such as social exclusion, social cohesion and social capital. The course of social inclusion is influenced by the integration policy of each country, but also by other standards adopted at EU level. With the development of globalization trends and advancing democracy, this issue has become the center of attention and is deliberated at a large number of national and global fora, searching for additional mechanisms and instruments. The aim of this study was to point out some contexts related to the issue of social inclusion in the field of social exclusion, which is associated with the emergence of excluded localities as a source of other negative social manifestations. The case study aims to present an example of solving internal social inclusion of socially excluded persons, who have problems to adapt, with the aim to point to the temporal, spatial and financial demands of the project, it highlights the causes, course and processes, which influence these integration efforts. Existing research and interpretation of the results of ongoing projects can bring significant benefits from the perspective of other applications and awareness of the professional public.

\section{References}

Atkinson, R. (2000). Citizenship and combating social exclusion in the context of the social state reform. Social studies, 2000(5), 43-61.

Bartram, D. (2019). Sociability among European Migrants. Sociological Research Online, 24(4), 557-574. doi: 10.1177/1360780418823213

Berger-Schmitt, R. (2000). Social Cohesion as an Aspect of the Quality of Societies: Concept and Measurement. EU Reporting Working Paper No. 14. Mannheim: Centre for Survey Research and Methodology (ZUMA).

Bourdieu, P. (1983). Forms of Capital. In J. G. Richardson (Ed.), Handbook of Theory and Research for Sociology of Education. New York: Greenwood Press.

Bucheli, J. R., Fontenla, M., \& Waddell, B. J. (2019). Return migration and violence. World development, 116, 113-124.

Coleman, J. S. (1988). Social Capital in the Creation of Human Capital. American Journal of Sociology, 94, 95-120.

Čsú. Český statistický úřad [Czech Statistical Office]. (n.d.). Retrieved March 3, 2019, from www.czso.cz 
De Haas, H. (2010). Migration and Development: A Theoretical Perspective. International Migration Review, 44(1), 227-264. doi: 10.1111/j.1747-7379.2009.00804.x

Drbohlav, D. (2016). We are not a nation of xenophobs. No country is ready for the next migration wave.

Easterly, W., Ritzen, J., \& Woolcock, M. (2006). Social Cohesion, Institutions, and Growth. Economics \& Politics, 18(2), 103-120.

Falk, I., \& Kilpatrick, S. (1999). What Is Social Capital? A Study of Interaction in a Rural Community. Launcestos: Centre for Research and Learning in Regional Australia.

Fokkema, T., \& de Haas, H. (2011). Pre- and Post-Migration Determinants of Socio-Cultural Integration of African Immigrants in Italy and Spain. International Migration, 53(6), 3-26. doi: 10.1111/j.1468-2435.2011.00687.x

Gambetta, D. (1988). Can We Trust Trust?. In D. Gambetta (Ed.), Trust: Making and Breaking Cooperative Relationships (pp. 213-237). New York: Basic Blackwell.

Gang, I. N., \& Stuart, R. C. (2000). Does Background Matter? The Transmission of Human Capital from a Planned to a Market Economy. International Migration Review, 34(2), 511-537. doi: 10.2307/2675912

Goodin, R. E. (1996). Institutions and their design. In R. E. Goodin (Ed.), The theory of institutional design (pp. 1-53). Cambridge: Cambridge University Press.

Großmann, K., Haase A., Rink, D., \& Steinführer, A. (2008). Urban Shrinkage in East Central Europe? Benefits and Limits of a Cross-National Transfer of Research Approaches. In M. Nowak, \& M. Nowosielski (Eds.), Declining Cities/Developing Cities. Polish and German Perspectives (pp. 77-99). Poznań: Instytut Zachodni.

Kelsey, P. N. (2019). Inclusion, exclusion or indifference? Redefining migrant and refugee host state engagement options in Mediterranean 'transit' countries. Journal of Ethnic and Migration Studies, 45(1), 42-60.

Kolibová, H. (2008). Sociální politika 2 [Social politics 2]. Opava: Optys.

Labor Office of the Czech Republic. (n.d.). Retrieved March 10, 2019, from https://portal.mpsv.cz

Layte, R., \& Whelan, Ch. T. (2003). Cumulative disadvantage or individualisation? A comparative analysis of poverty risk and incidence. European Societies, 4(2), 209-233.

Leonardi, R. (2005). Cohesion Policy in the European Union: The Building of Europe. Hampshire, New York: Palgrave Macmillan. 
Levitas, R. (2000). What is Social Exclusion?. In D. Gordon, \& P. Townsend (Eds.), Breadline Europe: The Measurement of Poverty (pp. 357-383). Bristol: The Policy Press.

Lewis, O. (1969). Culture of Poverty. In D. P. Moynihan, On Understanding Poverty: Perspectives from the Social Sciences (pp. 187-220). New York: Basic Books.

Lisabonská strategie pro růst a zaměstnanost [Lisbon Strategy for Growth and Jobs]. (2004). Retrieved March 10, 2019, from http://ec.europa.eu/growthandjobs/pdf/kok_ report_cs.pdf

Lister, R. (2003). The Idea of Social Inclusion. Speach presented at Social Inclusion Research Conference, March 27-28, in Ottawa.

Massey, D. S., \& Denton, N. A. (1985). Spatial Assimilation as a Socioeconomic Outcome. American Sociological Review, 50(1), 94-106. doi: 10.2307/2095343

Mouzelis, N. (1995). Strategies of Integration and Social-Cultural Differentiation. Copenhagen: CID (Centre for Social Integration and Differentiation).

Narayan, D. (1999). Bonds and Bridges: Social Capital and Poverty. Washington, DC: World Bank, Poverty Reduction and Economic Management Network, Poverty Division.

Navrátil, P., \& Šimíková, I. (2002). Assessment of projects aiming at reducing the risk of social exclusion of the Roma population. Part I. Typology of projects. Prague: Research Institute for Labour and Social Affairs.

Pajnik, M. (2019). Autonomy of migration and the governmentality of plastic borders. Dve domovini, 49, 125-141. doi: 10.3986/dd.v0i49.7257

Putnam, R. D. (1995). Bowling Alone: America's Declining Social Capital. Journal of Democracy, 6(1), 65-78.

Pūraitè, A., Seniutienè, D., \& Greičius, S. (2017). Managing State Border in the Context of Migration Crisis in Europe: Lithuanian Case. Montenegrin Journal of Economics, 13(3), 31-42. Retrieved from https://repository.mruni.eu/handle/007/15574

Reslow, N. (2019). Horizontal and Vertical Diversity: Unintended Consequences of EU External Migration Policy. Italian Journal of International Affairs, 54(1), 31-44. doi: 10.1080/03932729.2019.1548840

Rodgers, G. (1995). What is special about a social exclusion approach?. In G. Rogers, Ch. Gore, \& J. B. Figueiredo, Social exclusion: rhetoric, reality, responses (pp. 43-56). Geneva: The International Institute for Labour Studies. 
Room, G. J. (1999). Social Exclusion, Solidarity and the Challenge of globalization. International Journal of Social Welfare, 8(3), 166-174.

Sampson, R. J. (1988). Local Friendship Ties and Community Attachment in Mass Society: A Multilevel Systemic Model. American Sociological Review, 53(5), 766-779.

Sartori, G. (2005). Pluralism, multiculturalism and immigration. Brno: Dokořán.

Simon, P. (2003). France and the Unknown Second Generation: Preliminary Results on Social Mobility. International Migration Review, 37(4), 1091-1119.

Sirovátka, T. (2003). The labor market policy and social inclusion. Social studies, 2003(9), 87-105.

Statutory City of Ostrava. (n.d.). Retrieved March 10, 2019, from https://www.ostrava. cz/cs/podnikatel-investor/projekty-mesta-ostravy/projekty-mesta-ostravy/socialni-inkluze-ostrava

Strategický plán sociálního začleňování Ostrava, 2015-2018. (n.d.). Retrieved March 10, 2019, from https://socialnizaclenovani.ostrava.cz

Topinka, D. (2015). Survey on the feeling of safety around the socially excluded localities and other risk locations in Ostrava. Ostrava: SocioFactor. Retrieved March 10, 2019, from https://www.sociofactor.eu/vyzkumne-zpravy.php

Valenta, M., Lønning, M. N., Jakobsen, J., \& Župarić-Iljić, D. (2019). European Asylum Policies and the Stranded Asylum Seekers in Southeastern Europe. Journal of Refugee Studies, 32, 162-171. doi: 10.1093/jrs/fey063

Völker, B., Flap, H., \& Lindenberg, S. (2007). When Are Neighbourhoods Communities? Community in Dutch Neighbourhoods. European Sociological Review, 23(1), 99-114.

Yagmur, K. (2019). The concept of minority/minorities in the European national and supranational EU discourse. Multilingua, 38(2), 213-229. doi: 10.1515/multi-2018-0063

\section{Author}

prof. PhDr. Hana Vykopalová, CSc.

Faculty of Public Policies in Opava, Silesian University in Opava Institute of Pedagogical and Psychological Sciences Bezručovo nám. 885/14, 74601 Opava, Czech Republic hana.vykopalova@fvp.slu.cz 